\title{
Internal Voltage In A Conducting Closed Hollow Cylinder With An Attached End Plate Subjected To A Direct Lightning Strike
}

M. M. Ong, R. A. Anderson

June 1, 2000

U.S. Department of Energy

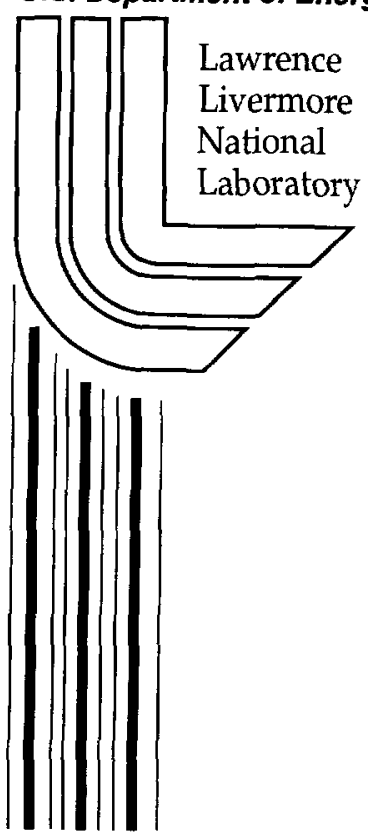




\section{DISCLAIMER}

This document was prepared as an account of work sponsored by an agency of the United States Government. Neither the United States Government nor the University of California nor any of their employees, makes any warranty, express or implied, or assumes any legal liability or responsibility for the accuracy, completeness, or usefulness of any information, apparatus, product, or process disclosed, or represents that its use would not infringe privately owned rights. Reference herein to any specific commercial product, process, or service by trade name, trademark, manufacturer, or otherwise, does not necessarily constitute or imply its endorsement, recommendation, or favoring by the United States Government or the University of California. The views and opinions of authors expressed herein do not necessarily state or reflect those of the United States Government or the University of California, and shall not be used for advertising or product endorsement purposes.

This work was performed under the auspices of the U. S. Department of Energy by the University of California, Lawrence Livermore National Laboratory under Contract No. W-7405-Eng-48.

This report has been reproduced directly from the best available copy.

Available electronically at http://www.doc.gov/bridge

Available for a processing fee to U.S. Department of Energy

And its contractors in paper from

U.S. Department of Energy

Office of Scientific and Technical Information

P.O. Box 62

Oak Ridge, TN 37831-0062

Telephone: (865) 576-8401

Facsimile: (865) 576-5728

E-mail: reports@adonis.osti.gov

Available for the sale to the public from

U.S. Department of Commerce

National Technical Information Service

5285 Port Royal Road

Springfield, VA 22161

Telephone: (800) 553-6847

Facsimile: (703) 605-6900

E-mail: orders@ntis.fedworld.gov

Online ordering: http://www.ntis.gov/ordering.htm

OR

Lawrence Livermore National Laboratory

Technical Information Department's Digital Library

http://www.llnl.gov/tid/Library.html 


\title{
Internal Voltage In A Conducting Closed Hollow Cylinder \\ With An Attached End Plate \\ Subjected To A Direct Lightning Strike
}

\author{
Mike M. Ong \\ Robert A. Anderson \\ June 2000
}

\section{Summary}

The interior voltage of a large metal can with thick walls struck directly by lightning was estimated using diffusion theory, aperture slot voltage theory, and experimental data. The hollow cylinder is closed at both ends. One end has a cap that is welded to the cylinder wall making a continuous electrical interface. The other end consists of a circular plate that is pressed into the cylinder wall and held under pressure with a threaded ring. From our experience with coupling measurements, this joint will be a weak link. It will allow more current to leak into the interior than from diffusion through the walls. Because the joint was designed for mechanical purposes, the electrical properties, such as continuity around the circumference, are not well controlled. Therefore, it is difficult to determine a single voltage attributed to this joint design with varying electrical characteristics. Instead, we will make a best effort of bounding the problem using both analytical calculations and data from tests of similar structures.

The calculated internal cylinder voltage subjected to an extreme lightning strike from current diffusing through the wall is 19 volts. We estimate that the press-fit end plate will increase this voltage by a factor of about two to ten. The internal voltage is expected to be between

$$
40 \text { and } 200 \text { volts. }
$$

This uncertainty can be reduced by making coupling and high-current measurements on a number of cans or by redesigning the cap to include electrical contacts. However, given that the critical components inside the cylinder are insulated to at least $3.5 \mathrm{kV}$, improving the joint design is unnecessary. The safety factor using the worst-case maximum interior voltage is 18 and is sufficient. A higher safety margin can be achieved by keeping the joint clean and under pressure.

\section{Introduction}

The hollow cylinder under evaluation is 6 feet long, 16 inches in diameter, and 0.5 inch thick. (See Figure 1.) Our goal is to determine the maximum internal voltage in the cylinder when directly struck by lightning as defined in Reference [1]. This extreme $(1 \%)$ lightning strike has characteristics that include a peak current of $200 \mathrm{kA}$, duration of $500 \mu \mathrm{s}$, and a rise rate of $400 \mathrm{kA} / \mu \mathrm{s}$. The cylinder is closed on both ends with 0.5 inch thick circulator plates. One end cap is welded to the cylinder wall. The other end has a circular plate that is pressed into the cylinder wall and held under pressure with a threaded ring. (See Figure 2.)

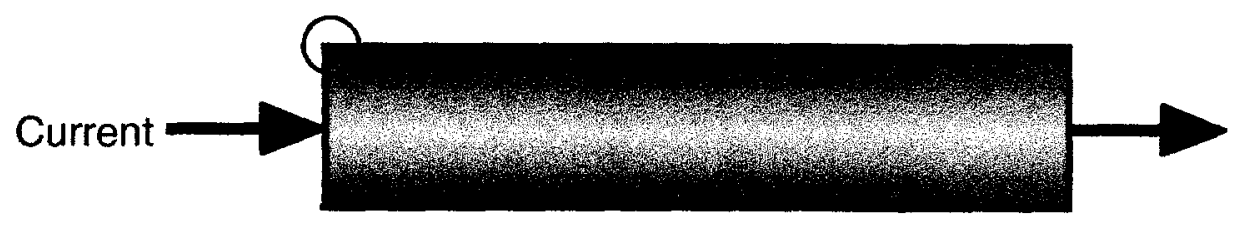

Figure 1. Internal voltages will be generated in the closed hollow cylinder when struck by lightning. 
From our experience hardening weapons components against electromagnetic energy, we must assume that this joint will be the weak link. While this joint can carry high current, it was not designed be an electrical interface. Therefore, the electrical properties are not controlled and will vary. We will estimate the range of voltages that will be generated at the joint for various conditions.

The highest internal voltage will be produced when an end piece is electrified. This potential difference on the interior of the cylinder will be determined by evaluating three mechanisms: diffusion through end caps, diffusion through wall and leakage at the pressfit joint.

Components inside of the cylinder will pickup additional voltage from electromagnetic fields that penetrate the case. However, the energy derived from the EM fields will be considerably less than from contacting the end caps [2]. Therefore, we will concentrate on calculating only the maximum case voltage.

The electrical properties of the case influence the diffusion and joint voltage. For our situation, the material is stainless steel. This type of steel has relatively low conductivity and permeability and will produce higher voltages than many other types of metal. However, it has excellent corrosion resistance, and we will see why this is important in the next section.

The joint voltage depends on mechanical properties, such as the geometry that determines the contact path length, gap size, surface finish and surface coating, and number and spacing of the contact points and area. Figure 3 summarizes the points that have been discussed.

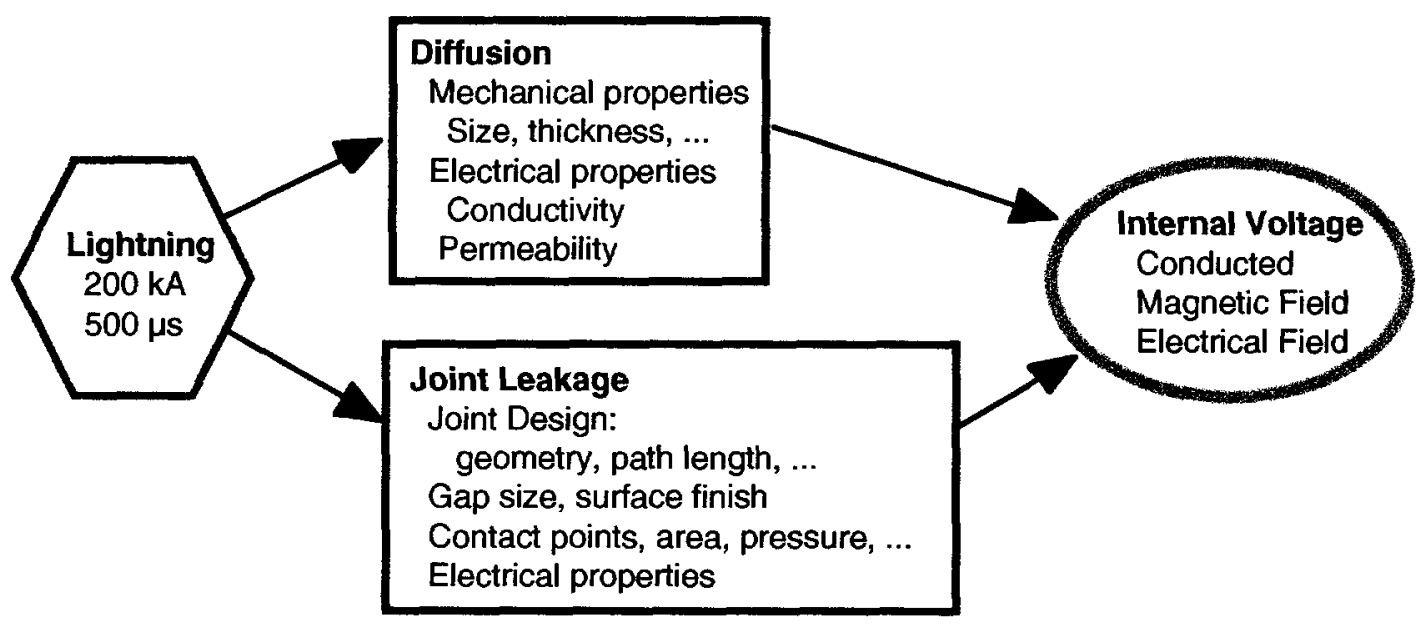

Figure 3. The internal voltage is affected by a number of factors including the mechanical and electrical properties of the case and joint. 
While complex, the diffusion voltage can be calculated making a few assumptions. Determining the exact joint voltage is much more difficult. Instead we will bound our answer by calculating the voltage under various assumptions and examine relevant test data. A simplified circuit is shown in Figure 4.

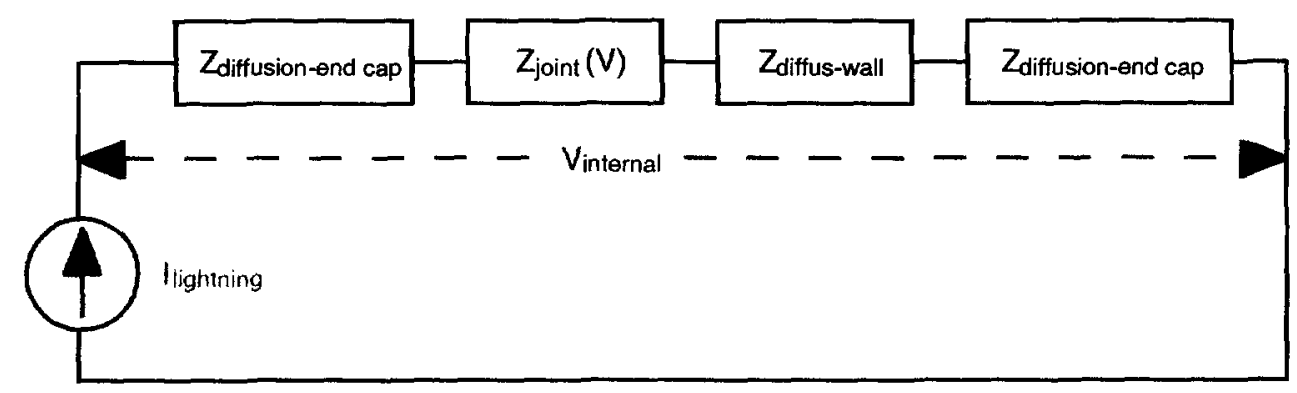

Figure 4. Simplified electrical circuit identifying the components of the internal voltage.

\section{Diffusion Voltage}

The diffusion equation for a conducting cylinder subjected to a direct lightning strike was derived from Maxwell's equations by Johnson, Warne, and Chin [3]. Because the case is made of stainless steel, the linear model was chosen. The exact solution for the planar diffusion equation contains a lengthy residue series. A conservative simplification was also offered and is used in our calculations.

The voltage, $V$, in the cylinder of length $2 h$, radius $b$, with welded end caps all with wall thickness $\Delta$ truck by lightning current $I$, can be calculated by

$$
V=2\left\{\frac{I}{2 \pi \sigma \Delta}\left[\ln \left(\frac{b}{\Delta \mathrm{e}^{-\gamma}}\right)+\frac{h}{b}\right]\left[\frac{\sigma \Delta E_{x}}{\mathrm{~h}_{\mathrm{o}}}\right]_{p l}\right\}
$$

where $\sigma$ is the conductivity, and $\gamma$ is the Euler constant. The second term in square

$$
\frac{\sigma \Delta}{\mathrm{h}_{\mathrm{o}}} E_{x}(t) \approx \frac{\tau_{f}}{\tau_{f}-\tau_{c}}\left[\mathrm{e}^{-t / \tau_{f}}-\mathrm{e}^{-t / \tau_{c}}\right]
$$

bracket can be estimated in a number of ways. The one we chose was where $\tau_{f}$ is the is the duration of the lightning pulse measured at the half amplitude. $\tau_{c}$ is a circuit time

$$
\tau_{c}=\frac{\sigma \mu \Delta^{2}}{6}
$$

constant used in the simplification and closely related to the diffusion response time. The permeability $\mu$ is set to $\mu_{\mathrm{o}}$ for our stainless steel case. The following table lists the value for the parameters used in the calculation. Figure 5. shows the calculated internal voltage with a peak of 19 volts. 


\begin{tabular}{|l|l|}
\hline Cylinder length, $2 h$ & 6 feet \\
\hline Cylinder radius, $b$ & 8 inches \\
\hline Wall thickness, $\Delta$ & 0.5 inch \\
\hline Resistivity, $1 / \sigma$ & $7.2 \times 10^{-5} \Omega \mathrm{cm}$ \\
\hline Lightning current, $I$ - peak & $200 \mathrm{kA}$ \\
\hline Lightning duration, $\tau_{f}-$ full width half max & $500 \mu \mathrm{s}$ \\
\hline Permeability, $\mu_{\mathrm{o}}$ & $1.26 \times 10^{-6} \mathrm{H} / \mathrm{m}$ \\
\hline
\end{tabular}

Table 1. Cylinder values used to determine the internal voltage.

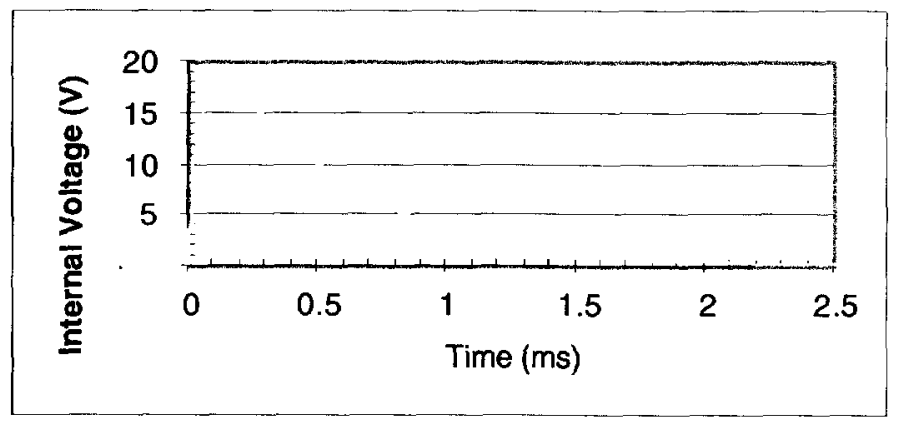

Figure 5. The peak potential is 19 volts for the cylinder subjected to a $1 \%$ lightning strike considering only diffusion current.

This theory was checked by Sandia National Laboratory with experiments [4]. For our cylinder, the maximum internal voltage must include a joint voltage.

\section{Joint Leakage}

Current diffusing through a conductive metal is exponentially attenuated because of the internal electric field cancellation and energy absorption. However, the small volume of material that encompasses the joint will appear to be more porous. The contact area even under pressure will be smaller than the cross section of the cylinder wall. This reduced thickness will increase the resistance. In the worst case scenario, significant gaps might exist that will raise the joint voltage even higher. However, voltage breakdown will occur in the gap and limit the voltage that develops. When all these conditions will exist to some degree, a well designed and maintained joint will not generate voltages that are a threat.

Our analysis consists of evaluating the joint design, determining the slot impedance in a worst case configuration, calculate breakdown voltage for various gap sizes, and comparing the results against data from a series of SNLA experiments.

The joint design is complex with a number of bends and a path length from the outer surface to the inner surface that is greater than 0.5 inches. The longer path length produces a larger contact area. This design should reduce the contact resistance better than a straight butt joint [5].

The worst case configuration occurs if the end plate does not contact the case. This requires that the plate diameter be smaller than the case inner diameter and is 
centered in the case. The bottom of the circular plate must also be separated from the case shelf. This could happen if the pressure was reduced to the point where the o-ring lifts the plate off the shelf. While this condition is extremely unlikely, we will evaluate this scenario to determine the upper limit for the joint voltage.

The slot inductance can be estimated using the following formula for a coaxial configuration.

$$
L=\frac{\mu}{2 \pi} \ln \left(\frac{r_{\text {outer }}}{r_{\text {inner }}}\right) \text { thickness }
$$

For a thickness of 0.5 inches, an outer radius of 8 inches, and a gap of 1 mil, the inductance is less than a pico-Henry. Therefore the voltage developed across this gap from a lightning strike with a rise rate of $400 \mathrm{kA} / \mu \mathrm{s}$ is less than a volt. The voltage potential throughout the joint is essentially the same. This will allow arcs to form in many locations. The gap size will determine the maximum joint voltage that can be sustained before an arc forms. Once the plasma channel is fully established, the joint voltage will be effected by the impedance of each channel, which is non-linear, and by the number of channels.

An estimate of the breakdown voltage can be calculated using the dielectric strength of air, $5.5 \mathrm{kV} / \mathrm{cm}$, for the lightning waveform. For a gap of $1 \mathrm{mil}$, the breakdown voltage is 14 volts. This voltage could be higher if the joint was coated with a dielectric having a higher breakdown strength.

When the plasma channel(s) is fully established, the current is still concentrated around the ends of the arc. When compared with a joint where the mating surfaces are in direct contact over a large area, the effective cross section at the end of the channel is small, which increases the resistance. This localization of the current will increase the joint voltage.

$$
V=I R \approx I \rho \frac{\text { length }}{\text { cross } \sec t i o n}
$$

Therefore, it is the non-linear plasma channel voltage and the joint contact resistance that determine the potential developed in the joint. This will become clearer when we examine the experimental data.

Sandia National Laboratory tested different types of joints to determine the joint voltage when subjected to a lightning-like injected current [6]. (See Figure 6.) Their cylinder radius was 5 inches. Wall thickness was 0.5 inch except on one side of the simple butt joint. It was reduced to about 0.25 inch. The joint parameters investigated were gap versus no gap, light and high contact pressure, surface finish, and aluminum versus steel. 


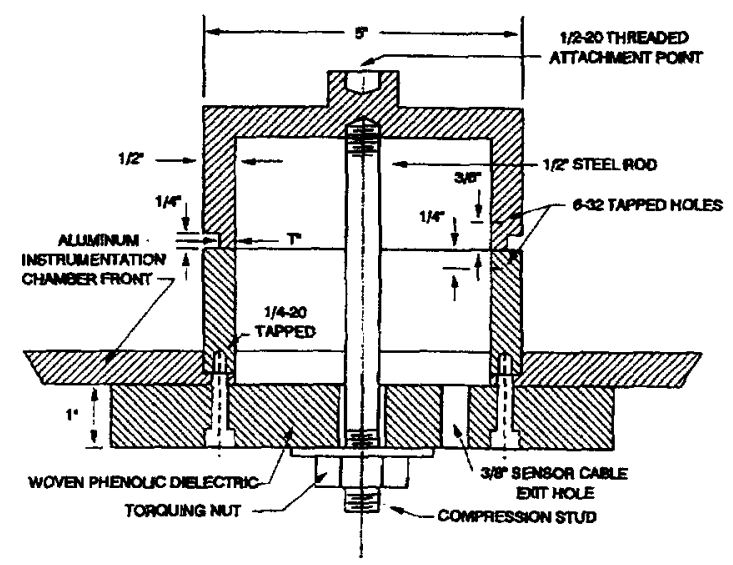

Figure 6. Butt joint test assembly used in lightning study.

The parameter that had the greatest effect was the present or absence of a gap. A 1 mil gap was created on aluminum by anodizing the joint. The resulting joint potential was a few hundred volts with the maximum level being 500 volts when subjected to a $200 \mathrm{kA}$ impulse. It is the localization of the current that drives up the voltage.

When the gap was eliminated, regardless of pressure, surface finish, or material type, the joint potential dropped dramatically to a few volts. The maximum level was 24 volts with the joint condition of light pressure and a smooth finish on steel.

There are three major differences between the configuration used in the Sandia test and of our cylinder: (1) the size (5-inch and 8-inch radius respectively), (2) joint thickness ( 0.25 versus 0.5 inch), and (3) joint design (simple butt versus complex respectively). All of these changes will decrease our joint voltage. Our cylinder will likely never develop a joint coating like the anodizing material, and will not generate the higher voltage levels.

\section{Conclusions and Recommendations}

The maximum internal cylinder potential is a combination of the diffusion voltage and the joint voltage. The diffusion voltage can be reasonably calculated. The joint voltage is more difficult to determine and an estimate was extracted from test data of a similar assembly. The predicted case voltages produced by an extreme lightning strike are summarized in Table 2.

\begin{tabular}{|c|c|c|c|}
\hline $\begin{array}{c}\text { Diffusion Voltage } \\
\text { Our Case }\end{array}$ & $\begin{array}{c}\text { Joint Voltage Sandia } \\
\text { Test Assembly }\end{array}$ & $\begin{array}{c}\text { Case Voltage w/ } \\
\text { Sandia Assembly }\end{array}$ & $\begin{array}{c}\text { Est. Case Voltage } \\
\text { w/ Our Joint }\end{array}$ \\
\hline 19 & $\leq 24(1)$ & $\leq 43(1)$ & 40 \\
\hline 19 & $\leq 500(2)$ & $\leq 519(2)$ & $200(3)$ \\
\hline
\end{tabular}

(1) No gap (2) 1 mil gap formed with dielectric coating (3) 1 mil gap no dielectric coating

Table 2. Maximum interior case voltage depends mainly on the gap in the joint.

The cylinder being evaluated is more robust against lightning than the Sandia Joint Test Assembly for reasons described in the last section. The cylinder will generate a lower joint voltage than the levels recorded in the Sandia joint tests. In the situation where the plate is in contact with the case, we expect the joint voltage to be slightly lower because of the larger contact area. In the situation where a gap is present in the cylinder 
joint, we expect the voltage to be also lower. Our gap would be filled with air rather than with a higher strength dielectric as in the Sandia test. Even if a gap exists, realistically the plate should touch the case in at least one point. Considering the differences between the cylinder being evaluated and the Sandia Joint Test Assembly, the interior voltage of the cylinder is estimated to be between

\section{0 and 200 volts.}

This uncertainty can be reduced by making coupling and high-current measurements on a number of cans or by redesigning the cap to include electrical contacts. However, given that the critical components inside the cylinder are insulated to at least $3.5 \mathrm{kV}$, improving the joint design is unnecessary. The safety factor using the worst-case maximum interior voltage is 18 and is sufficient.

A well maintained joint will not generate voltages that are a threat. The interior case voltage should fall into the lower range of our prediction if the joint is kept clean and under pressure.

\section{Acknowlegment}

We wish to acknowledge the insights on the joint voltage provided by

Dr. Marvin Morris. He directed us to Reference [6] and suggested the arc breakdown limit in the gap.

\section{References}

[1] Fisher, R. J., M. A. Uman, "Recommended Baseline Direct-Strike Lightning Environment for Stockpile-to-Target Sequences", Sandia Report, May 1989, SAND89-0192.

[2] Maxwell, Keith J, "Prediction of Lightning-Induced Voltages in Aircraft Electrical Circuits", IEEE 1975 International Symposium on Electromagnetic Compatibility, San Antonio, TX, 1-9 Oct 1975, p 3Bic/1-8.

[3] Johnson, William A., Larry K. Warne, and Kenneth C. Chen, "Linear Diffusion and Internal Voltages in Conducting Enclosures Subjected to A Direct Lightning Strike", Electromagnetics, 15:189-207, 1995.

[4] Johnson, William A., Sandia National Laboratory, conversation and vugraph, June 2000.

[5] Mottahed, Behzad D., Souran Manoochehri, “ Joint Design Methodology Based on the Electromagnetic Shielding Effectiveness Capabilities", IEEE Transactions on Components, Packaging, and Manufacturing Technology, Part B, Vol 19, No1, pp 238-47, Feb 1996.

[6] Dinall, Michael A, Richard J. Fisher, "Voltages Across Assembly Joints Due to Direct-Strike Lightning Currents", Sandia National Laboratory, SAND93-0788, Aug 1994. 


\section{Distribution}

Pantex Plant

Doug Miller

Alan Scruggs

Corey Strickland

DOE

Don Burnell

John Fredlund

Willy Molina

Bob Young

Sandia National Lab

Corey Knapp

Kim Merewether

Los Alamos National Lab

Richard Yactor

Lawrence Livermore National Lab

Bob Anderson

Terry Bevers

Wes Davis

Jerry Dow

Karl Freytag

Joe Galkowski

Dave Goerz

Glen James

Marvin Morris - Consultant

Mike Ong

Mike Wilson

DNFSB

William White 